\title{
Ingestão de matéria seca por novilhas de corte em pastagem de milheto
}

\author{
Dry matter intake by beef heifers in a Pearl Millet pasture
}

\section{Denise Baptaglin Montagner ${ }^{\mathrm{I}}$ Marta Gomes da Rocha ${ }^{\mathrm{II}}$ Teresa Cristina Moraes Genro ${ }^{\mathrm{II}}$ Carolina Bremm ${ }^{\text {IV }}$ Davi Teixeira dos Santos ${ }^{\text {IV }}$ Juliano Roman $^{\text {IV }}$ Dalton Roso $^{\text {IV }}$}

\section{RESUMO}

\begin{abstract}
Em pastagem de milheto (Pennisetum americanun (L.) Leeke), foram avaliadas a ingestão de matéria seca (MS da forragem por novilhas de corte e a massa de bocado. Utilizou-se o delineamento inteiramente casualizado com medidas repetidas no tempo, com dois tratamentos de massas de lâmina foliar $\left(600\right.$ e $1.000 \mathrm{~kg} \mathrm{ha}^{-1}$ de MS), mantidos por lotação contínua e com ajuste de carga, e três repetições de área. A ingestão de matéria seca foi estimada por meio do uso de óxido de cromo $\left(\mathrm{Cr}_{2} \mathrm{O}_{3}\right)$ como indicador da produção fecal e da fibra em detergente ácido indigestivel como indicador interno. Os parâmetros qualitativos avaliados na forragem foram a fibra em detergente neutro, a digestibilidade in vitro da matéria orgânica e o teor de proteína bruta. Bocados mais pesados foram observados quando o milheto foi manejado com $1.000 \mathrm{~kg} \mathrm{ha}^{-1}$ de MS de lâminas foliares, mesmo que as novilhas tenham ingerido a mesma quantidade de matéria seca, 1,8\% do peso corporal, nas duas massas de lâminas foliares. A pastagem de milheto manejada com massas de lâminas foliares de 600 ou $1.000 \mathrm{~kg} \mathrm{ha}^{-1}$ de MS proporciona aos animais em pastejo oportunidade semelhante de consumo de forragem.
\end{abstract}

Palavras-chave: fibra em detergente ácido indigestível, fibra em detergente neutro, óxido de cromo, Pennisetum americanum, produção fecal.

\section{ABSTRACT \\ It was evaluate the dry matter (DM) herbage intake by beef heifers and the bite mass on a Pearl Millet (Pennisetum americanun (L.) Leeke) pasture. The experimental design was completely randomized with repeated measures in time, two}

leaf blade mass (600 and 1,000kg ha-1 of DM), which were maintained by continuous stocking with variable stocking rate, and three replicate areas. The herbage intake was evaluated using chromic oxide $\left(\mathrm{Cr}_{2} \mathrm{O}_{3}\right)$ as a faecal production indicator and the acid detergent indigestible fiber as an internal indicator. The qualitative parameters evaluated in the forage were the neutral detergent fiber, in vitro organic mater digestibility and the crude protein content. The heavier bites were achieved in a Pearl Millet pasture managed with 1,000kg ha-1 of leaf blade dry matter (DM) even though the steers have eaten the same dry matter amount, $1.8 \%$ of live weight, in the two leaf blade mass. The Pearl Millet pasture managed with leaf blade herbage mass of 600 or $1,000 \mathrm{~kg} \mathrm{ha}^{-1}$ of DM provides to the grazing animals similar opportunity of herbage intake.

Key words: indigestible detergent acid fiber, detergent neutral fiber, chromic oxide, Pennisetum americanum (L.) Leeke, fecal production.

\section{INTRODUÇÃO}

Em pastagens formadas por plantas forrageiras tropicais, tais como o milheto (Pennisetum americanum (L.) Leeke), a seleção da forragem consumida está relacionada principalmente à distribuição de folhas verdes dentro dos horizontes de pastejo (STOBBS, 1973). A produção animal está diretamente associada à porcentagem de folhas, à digestibilidade e ao consumo de matéria seca digestível (VAN SOEST, 1994). Os animais em pastejo apresentam

'Faculdade de Ciências Agrárias, Universidade Federal da Grande Dourados (UFGD), Rodovia Dourados-Itahum, km 12, CP 533, 79804-970, Dourados, MS, Brasil. E-mail: dmontagner@yahoo.com.br. Autor para correspondência.

"IDepartamento de Zootecnia, Universidade Federal de Santa Maria (UFSM), Santa Maria, RS, Brasil.

"IEmbrapa Pecuária Sul, Bagé, RS, Brasil.

IVPrograma de Pós-Graduação em Zootecnia, UFSM, Santa Maria, RS, Brasil. 
preferência por lâminas foliares (HODGSON, 1990) e maiores níveis de produção animal são alcançados em pastagens com folhas verdes acessíveis no topo do dossel. A quantidade de forragem e, mais precisamente, a biomassa de folhas verdes, têm grande influência no consumo voluntário e, consequentemente, no desempenho dos animais.

$\mathrm{O}$ processo do pastejo e da ingestão de forragem pelos bovinos é complexo, pois depende de inúmeros fatores do meio, os quais afetam a quantidade e a qualidade da forragem disponível e a capacidade do animal em colher esta forragem. As folhas possuem um duplo papel na interface planta-animal, representando a superfície responsável pela eficiência fotossintética e o substrato de maior qualidade na dieta animal (CARVALHO et al., 2001).

A pastagem de milheto, no verão, é uma alternativa ao uso da pastagem nativa, pois produz até cinco vezes mais forragem que o campo nativo do Rio Grande do Sul (RIZO et al., 2004) e permite incrementar o ganho de peso vivo por área e a taxa de lotação. Em pastejo, a composição bromatológica do milheto varia no decorrer do seu ciclo e o ganho de peso animal não se mantém constante (SANTOS et al., 2005). A variação no ganho, decorrente da variação no consumo voluntário em gramíneas tropicais, ocorre devido às limitações físicas ao processo de apreensão de forragem, provocadas, parcialmente, pelo expressivo alongamento dos colmos (Da SILVA, 2004).

Esse estudo foi conduzido com o objetivo de avaliar o efeito da estrutura do dossel de pastos de milheto, manejados sob duas massas de lâminas foliares (600 e 1.000 $\mathrm{kg} \mathrm{ha}^{-1}$ de MS), sobre a ingestão de matéria seca por novilhas de corte.

\section{MATERIAL E MÉTODOS}

$\mathrm{O}$ experimento foi conduzido em área do Departamento de Zootecnia da Universidade Federal de Santa Maria (UFSM), localizada na Depressão Central do Rio Grande do Sul, com altitude de $95 \mathrm{~m}$ (29 $43^{\prime}$ S, 5342'O). O clima da região é Cfa (subtropical úmido) conforme classificação de Köppen. Os dados da precipitação pluviométrica média mensal, da radiação global e das temperaturas mínima, média e máxima, durante período experimental, foram obtidos na Estação Meteorológica da UFSM. A temperatura média no período experimental foi de $23,5^{\circ} \mathrm{C}$, com mínima de $18,7^{\circ} \mathrm{C}$ e máxima de $28,3^{\circ} \mathrm{C}$. A insolação do período foi de 412,8 horas e a precipitação pluviométrica média, de 111,6mm.

O solo da área experimental é classificado como Argissolo Vermelho distrófico arênico (EMBRAPA, 1999). Aárea experimental foi constituída por seis hectares com seis subdivisões mais uma área de 1,8 ha. A semeadura foi realizada pelo sistema direto, em 28 de novembro de 2001, utilizando-se $35 \mathrm{~kg} \mathrm{ha}^{-1} \mathrm{de}$ sementes de milheto (Pennisetum americanum L. Leeke), 280 $\mathrm{kg} \mathrm{ha}^{-1}$ da fórmula 5-20-20 (NPK). Foram aplicados em cobertura $130 \mathrm{~kg} \mathrm{ha}^{-1}$ de nitrogênio $(\mathrm{N})$, na forma de uréia, nas datas de 23/01, 11/02 e 21/03/2002.

Os tratamentos consistiam de duas massas de lâminas foliares: $600 \mathrm{e} 1.000 \mathrm{~kg} \mathrm{ha}^{-1}$ de matéria seca de folhas, em pastagens manejadas sob lotação contínua, com taxa de lotação variável (MOTT \& LUCAS, 1952). Os animais experimentais foram novilhas raça Charolês e mestiças Charolês x Nelore, com idade média de 15 meses e peso médio inicial de $230 \mathrm{~kg}$. Foram utilizados três animais-teste por repetição (piquete) e um número variável de animais reguladores para manter as massas de lâminas foliares pretendidas. As massas de lâminas foliares foram impostas no decorrer dos primeiros 26 dias de utilização da pastagem. O delineamento experimental utilizado foi o inteiramente casualizado, com medidas repetidas no tempo (períodos de pastejo), com dois tratamentos (massas de lâminas foliares) e três repetições (piquetes). O período experimental foi subdividido em três períodos, de 31/ 12/2001 a 25/01/2002 (1 a 26 dias); de 26/01 a 23/02/2002 ( 27 a 54 dias) e de 24/02 a 04/04/2002 (55 a 94 dias).

A massa de forragem foi estimada a cada 15 dias, pelo método de estimativa visual com dupla amostragem, em 20 pontos aleatórios por piquete. $\mathrm{Da}$ forragem proveniente dos cortes foi retirada uma subamostra e feita a separação manual dos componentes (colmos + bainhas, lâminas foliares, material morto). A massa de lâminas foliares foi obtida pela multiplicação da massa de forragem e da porcentagem de lâminas foliares presentes na pastagem. Com base nas porcentagens de lâminas foliares e colmos + bainhas, foi determinada a relação lâmina: colmo + bainha (Relação L:C). A taxa de acúmulo diário de forragem foi estimada utilizando-se três gaiolas de exclusão por unidade experimental. O corte da forragem foi realizado rente ao solo, com um quadrado de $0,25 \mathrm{~m}^{2}$ de área. Nesta ocasião também foram tomadas as medidas de altura do dossel $(\mathrm{cm})$.

A avaliação da ingestão de matéria seca foi realizada nos dias 14 a 25/01; 11 a 22/02 e 11 a 22/03 de 2002. Foi utilizado o óxido crômico $\left(\mathrm{Cr}_{3} \mathrm{O}_{2}\right)$ como marcador externo para determinação da produção fecal dos animais em pastejo e a fibra em detergente ácido indigestível (FDAI, descrito por MENDES et al., 2001) como indicador interno para determinação da digestibilidade da forragem. Dois animais-teste foram dosificados, via oral, com dez gramas de óxido crômico, divididas em duas doses diárias, seguindo-se a técnica recomendada por PENNING (2004). O nível de cromo 
nas fezes secas foi determinado por espectrofotometria de absorção atômica (WILLIANS et al., 1962). O consumo voluntário de MS avaliado (CMS, em kg dia-1) foi expresso, também, em porcentagem do peso vivo (CPV) e em peso metabólico (CPM).

As variáveis qualitativas do milheto foram determinadas em amostras coletadas pela técnica de simulação de pastejo (EUCLIDES et al., 1992), utilizando-se dois avaliadores treinados por unidade experimental. O teor total de nitrogênio $(\mathrm{N})$ da forragem foi determinado pelo método micro Kjedahl (método 984.13, AOAC, 1995), pelo qual foram calculados os teores de proteína bruta da forragem. A digestibilidade in vitro da matéria orgânica (DIVMO) foi determinada por meio da técnica descrita por TILLEY \& TERRY (1963). O teor de FDN da forragem foi determinado de acordo com a técnica descrita pela AOAC (1995). A matéria orgânica digestível foi determinada por meio da multiplicação do teor de matéria orgânica pela sua digestibilidade, sendo obtido o teor de MO digestível (MOD). O consumo de PB dividido pelo consumo de MOD estimou o conteúdo de PB da dieta ( $\mathrm{g} \mathrm{PB} \mathrm{kg}^{-1}$ MOD).

Os valores de massa de bocado foram estimados pela equação adaptada de ALLDEN \& WHITTAKER (1970): massa do bocado (g MO) = consumo de matéria seca $\left(\mathrm{g} \mathrm{dia}^{-1}\right) /($ taxa de bocados $\left(\text { boc. } \min ^{-1} \text { ) x tempo de pastejo }\left(\min . \mathrm{dia}^{-1}\right)\right)^{*}$ teor de matéria orgânica da forragem aparentemente consumida; em que o consumo de MS ( $\left.\mathrm{g} \mathrm{dia}^{-1}\right)$ foi determinado com o uso do óxido de cromo como indicador (WILLIANS et al., 1962). As determinações do tempo de pastejo e da taxa de bocados (HODGSON, 1982) foram realizadas em três animais-teste em cada repetição experimental nos dias 18 e 19/01; 15 e 16/02; 15 e 16/03. O número estimado de bocados por dia foi obtido pela multiplicação da taxa de bocados pelo tempo de pastejo.

Os dados foram submetidos à análise de variância e ao teste F a 5\% de significância, utilizandose o procedimento PROC MIXED e, quando detectadas diferenças, as médias foram comparadas pelo teste $t$ de Student (PDIFF). As variáveis foram analisadas por meio do programa estatístico Statistical Analysis System (SAS, 1996).

O modelo matemático referente à análise dos parâmetros estimados no pasto foi:

$\mathrm{Yijk}=\mu+\mathrm{MLFi}+\mathrm{Pj}+\mathrm{Rk}(\mathrm{MLF}) \mathrm{i}+(\mathrm{MLF} * \mathrm{P}) \mathrm{ij}+\Sigma \mathrm{ijk}, \mathrm{em}$ que Yijk = variáveis dependentes; $\mu=$ média de todas as observações; MLFi = efeito da i-ésima massa de lâmina foliar; $\mathrm{Pj}$ = efeito do j-ésimo período; $\mathrm{Rk}$ (MLF)i = efeito da $\mathrm{k}$-ésima repetição dentro da i-ésima massa de lâmina foliar (resíduo A); MLF*Pij = efeito de interação i-ésima massa de lâmina foliar x j-ésimo período; $\Sigma$ ijk = erro experimental (erro B). Para as estimativas da ingestão de matéria seca, peso e taxa de bocados, os animais (dois testes por repetição de área) também foram inseridos no modelo.

\section{RESULTADOS E DISCUSSÃO}

Não foi observada interação entre massas de lâminas foliares e períodos de avaliação do milheto para as variáveis estudadas $(\mathrm{P}>0,05)$. A capacidade de ingestão da forragem pelos animais é influenciada pela disposição das partes da planta no horizonte vertical (CARVALHO et al., 2001), notadamente as lâminas foliares. Essa disposição, conhecida como a estrutura vertical do dossel, pode ser descrita pelos valores de massa de forragem, altura do dossel e densidade de forragem. Para as duas massas de lâminas foliares avaliadas, a estrutura do dossel diferiu no que diz respeito à massa de forragem (Figura 1A) e altura do dossel (Figura 1B), que foram menores e maiores em pastos manejados com 600 e $1.000 \mathrm{~kg} \mathrm{ha}^{-1}$ de MS de lâminas foliares, respectivamente. As ofertas de lâminas foliares, no entanto, foram similares $(\mathrm{P}=0,6398)$ nas massas de lâminas foliares avaliadas, com valores de 7,9 e $9,0( \pm 1,40) \mathrm{kg}$ de MS $100 \mathrm{~kg}^{-1}$ de PV, para 600 e 1.000 , respectivamente. Considerando que a oferta de forragem deve ser de três a quatro vezes o consumo estimado pelos animais em pastejo (HODGSON, 1990), pode-se supor que as ofertas de forragem médias não foram limitantes para a seleção e a ingestão de forragem.

A ingestão de matéria seca pelos animais em pastejo(Figura 1D) foi similar nas massas de lâminas foliares avaliadas e essa semelhança foi assegurada pelas alterações ocorridas no peso do bocado (Figura 1B) e na frequência de bocados. Animais mantidos em pastos com $1.000 \mathrm{~kg} \mathrm{ha}^{-1}$ de MS de lâminas foliares realizaram bocados mais pesados (Figura 1C). A frequência do bocado foi de 41 e 37 bocados.minuto ${ }^{-1}$ $(\mathrm{P}<0,05)$, respectivamente, em 600 e $1.000 \mathrm{~kg} \mathrm{ha}^{-1} \mathrm{de} \mathrm{MS}$ de lâminas foliares. Animais em pastos manejados com $600 \mathrm{~kg} \mathrm{ha}^{-1}$ de MS de lâminas foliares realizaram 1.530 bocados a mais que aqueles mantidos em pastos com $1.000 \mathrm{~kg} \mathrm{ha}^{-1}$ de MS que efetuaram 17.660 bocados dia ${ }^{-1}$. Assim, a ingestão de matéria seca foi resultado da forragem acumulada pelo consumo em cada uma das ações realizadas na menor escala do processo de pastejo, do bocado, e da frequência com que os animais os realizaram ao longo do tempo de pastejo (CARVALHO\& MORAES, 2005).

Em pastagens tropicais, a massa de lâminas foliares e a altura do dossel estão associadas com a facilidade com que o animal consegue alcançar as partes da planta preferíveis no pastejo. Em forrageiras tropicais, principalmente nos gêneros Panicum e Brachiaria, o maior desempenho animal, descrito pelos 


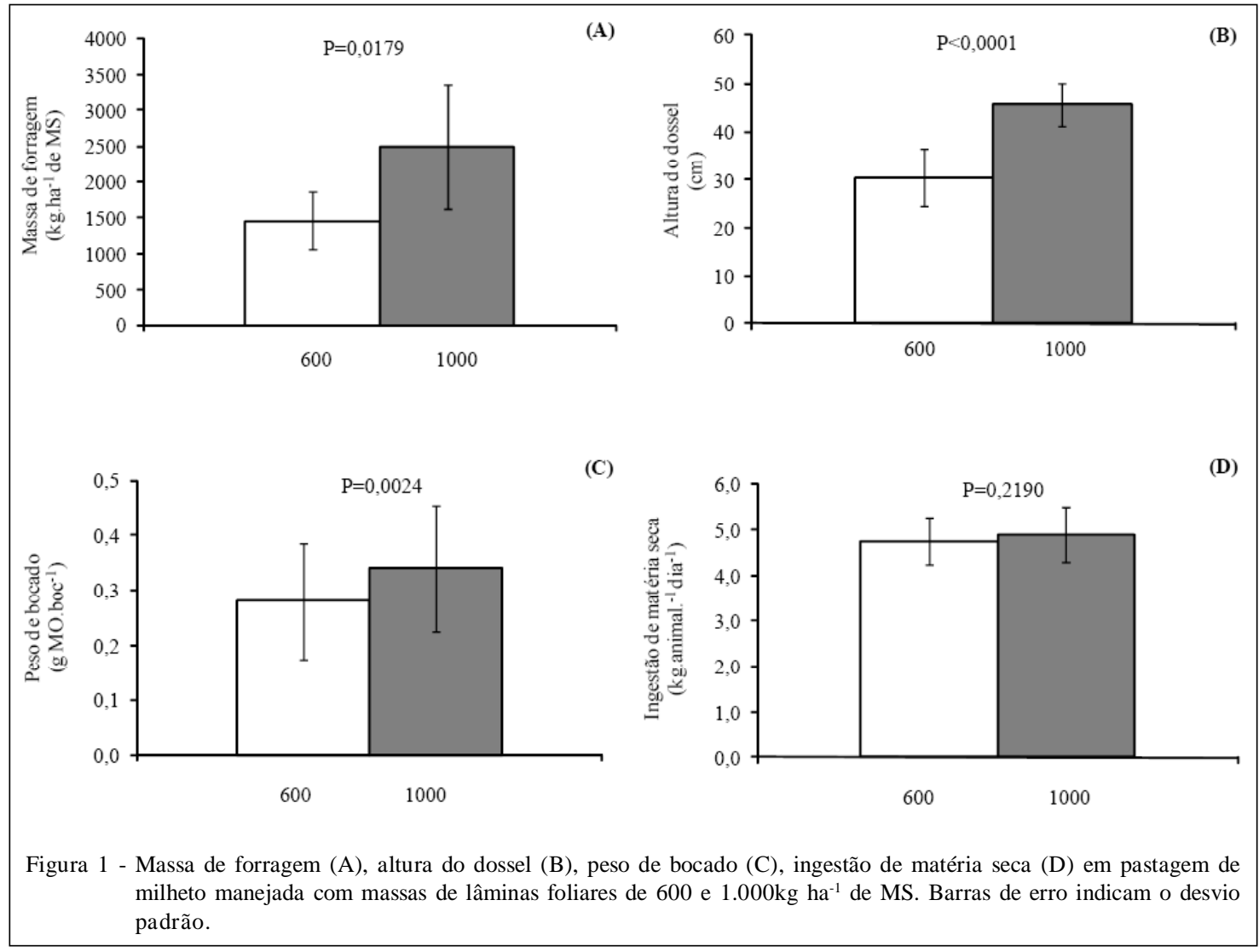

ganhos individual e por área, juntamente com as maiores taxas de ingestão de matéria seca, tem sido obtido em pastos mantidos com alturas variando de 30 a 45cm (FLORES et al., 2008; CARLOTO et al., 2009). Para o capim-Xaraés (Brachiaria brizantha cv. Xaraés), a massa de lâminas foliares associada a este intervalo de altura variou de 740 a $1.505 \mathrm{~kg} \mathrm{ha}^{-1}$ de MS (FLORES et al., 2008).

As alterações na estrutura do dossel durante o avanço do período experimental e no ciclo vegetativo do milheto modificaram a capacidade do animal em colher a forragem disponível, reduzindo a ingestão de matéria seca $(\mathrm{P}<0,05$; Tabela 1$)$. Com o avanço do período de utilização da pastagem de milheto, foram observadas redução na taxa de acúmulo $(\mathrm{P}=0,0077)$, na oferta de lâminas foliares $(\mathrm{P}<0,0001)$, na relação lâmina:colmo $(\mathrm{P}=0,0402)$ e na porcentagem de folhas ( $\mathrm{P}=0,0237$; Tabela 1$)$. O início do ciclo reprodutivo do milheto, que é influenciado principalmente pela diminuição da radiação global pode ter sido determinante para a redução na taxa de acúmulo de lâminas foliares. $\mathrm{O}$ menor acúmulo de folhas atua negativamente sobre a oferta de lâminas foliares e a relação lâmina:colmo do pasto (Tabela 1), as quais são características estruturais do dossel, que promovem modificações no hábito de pastejo e na ingestão de forragem (CARVALHO et al., 2007).

O teor de PB na forragem consumida foi menor no início da utilização da pastagem de milheto (Tabela 1). De acordo com o observado por KOLLET et al. (2006), o teor de PB na forragem diminui com o avanço do estádio de desenvolvimento do milheto. Assim, o período de aproximadamente 40 dias decorridos da semeadura até o início da utilização promoveu redução no teor de $\mathrm{N}$, pois as plantas estavam em crescimento livre, sem pastejo, o que pode ter causado o espessamento da parede de celular que, conforme VAN SOEST (1994) causa a redução do teor de nitrogênio solúvel e aumento dos teores de FDN. Com o início do pastejo, ocorreu a rebrotação da forragem existente e novas folhas foram produzidas (período de 27 a 54 dias), contribuindo para a elevação dos teores de PB e diminuição dos teores de FDN (Tabela 1). O teor médio de $\mathrm{PB}$, de 16,2\% (Tabela 1), poderia promover ganho individual de $1,7 \mathrm{~kg}$ animal ${ }^{-1} \mathrm{dia}^{-1}$ (NRC, 1996). O conteúdo médio de $\mathrm{PB}$ na dieta, no entanto, de $289 \mathrm{~g}$ $\mathrm{PB} \mathrm{kg} \mathrm{kg}^{-1}$ de MOD, pode ter acarretado perdas de proteína, gasto energético excessivo pelos microrganismos ruminais ou ainda transferência incompleta para o intestino delgado, o que acontece 
Tabela 1 - Características estruturais e qualitativas em pastos de milheto manejado em duas massas de lâminas foliares; ingestão de matéria seca e peso de bocados realizados pelas novilhas em pastejo

\begin{tabular}{|c|c|c|c|c|}
\hline \multirow{2}{*}{ Variáveis } & \multicolumn{3}{|c|}{ Dias após o início do pastejo--- } & \multirow{2}{*}{$\mathrm{CV}(\%)$} \\
\hline & 1 a 26 & 27 a 54 & 55 a 94 & \\
\hline Taxa de acúmulo $\left(\mathrm{kg} \mathrm{ha}^{-1} \mathrm{dia}^{-1} \mathrm{MS}\right)$ & $308,8 \mathrm{a}$ & $202,9 \mathrm{~b}$ & $62,2 \mathrm{c}$ & 21,1 \\
\hline Oferta diária ( $\mathrm{kg}$ matéria seca $100 \mathrm{~kg}^{-1}$ peso vivo) & $9,2 \mathrm{a}$ & $10,4 \mathrm{a}$ & $6,0 \mathrm{~b}$ & 34,5 \\
\hline Relação Lâmina:Colmo & $1,1 \mathrm{a}$ & $1,3 \mathrm{a}$ & $0,4 \mathrm{~b}$ & 20,2 \\
\hline Lâminas foliares (\%) & $48,6 \mathrm{a}$ & $40,5 \mathrm{a}$ & $23,9 \mathrm{~b}$ & 13,3 \\
\hline Proteína bruta $(\%)$ & $11,8 \mathrm{c}$ & $20,3 \mathrm{a}$ & $16,5 \mathrm{~b}$ & 13,7 \\
\hline Fibra em detergente neutro $(\%)$ & $68,4 \mathrm{a}$ & $58,6 \mathrm{~b}$ & $64,0 \mathrm{ab}$ & 9,1 \\
\hline Ingestão de matéria seca $\left(\mathrm{kg}\right.$ animal $\left.^{-1} \mathrm{dia}^{-1}\right)$ & $4,9 \mathrm{ab}$ & $5,3 \mathrm{a}$ & $4,3 \mathrm{~b}$ & 10,3 \\
\hline Ingestão de matéria seca (\% PV) & $2,0 \mathrm{a}$ & $1,8 \mathrm{ab}$ & $1,6 \mathrm{~b}$ & 9,6 \\
\hline Ingestão de matéria seca $\left(\mathrm{PV}^{0,75}, \mathrm{~kg}\right)$ & $79,6 \mathrm{a}$ & $75,2 \mathrm{ab}$ & $65,7 \mathrm{~b}$ & 9,7 \\
\hline Peso de bocados (g matéria orgânica bocado ${ }^{-1}$ ) & $0,43 \mathrm{a}$ & $0,21 \mathrm{~b}$ & $0,27 \mathrm{~b}$ & 7,2 \\
\hline
\end{tabular}

Letras minúsculas distintas na mesma linha diferem entre si pelo teste $\mathrm{t}(\mathrm{P}<0,05)$.

quando o conteúdo de PB excede 210g PB kg-1 de MOD (POPPI \& McLENNAN, 1995). Os teores de FDN (Tabela 1) foram variáveis durante o período de utilização da pastagem $(\mathrm{P}<0,05)$, sendo superiores a $60 \%$ no início (1 a 26 dias) e no final da utilização da forrageira (55 a 94 dias), o que, segundo VAN SOEST (1994) restringe o consumo de pasto pelos herbívoros. KOLLET et al. (2006) reportaram teores de FDN médios de $64 \%$ para três cultivares de milheto aos 49 dias de idade, próximo ao teor observado nos períodos inicial e final de utilização da pastagem (Tabela 1) no presente experimento. O conteúdo de FDN aumenta com o avanço da idade da planta, provavelmente em virtude da redução da porcentagem de lâminas e do aumento da proporção de colmos (relação L:C, no primeiro e último período, Tabela 1), elevando os componentes fibrosos (VAN SOEST, 1994).

A ingestão média de MS foi de $4,8 \mathrm{~kg} \mathrm{dia}^{-1}$ (Figura 1D e Tabela 1), inferior ao valor de $5,5 \mathrm{~kg} \mathrm{dia}^{-1}$ de MS, descrito pelo NRC (1996) como adequado para novilhas desta categoria. A baixa ingestão de MS pode ter sido influenciada pelo conteúdo de FDN (Tabela 1), considerado limitante físico da ingestão de forragem (VAN SOEST, 1994), uma vez que os valores de oferta de forragem não foram restritivos (Tabela 1), pois os níveis máximos de consumo e desempenho animal estão relacionados com oferta de forragem de cerca de duas a três vezes as exigências diárias de MS do herbívoro (HODGSON, 1990).

Os animais realizaram bocados mais pesados quando o milheto estava em estádio vegetativo (Tabela $1 ; \mathrm{P}<0,05)$, o que pode ser ter sido consequência da maior proporção de lâminas foliares (Tabela 1), facilitando a apreensão de forragem. Com o avanço do ciclo e a redução na proporção de lâminas foliares, os animais realizaram bocados menores, em média $0,24 \mathrm{~g}$ de $\mathrm{MO}$ boc $^{-1}$ e houve aumento na taxa de bocados, provavelmente pela menor manipulação do material ingerido (CARVALHO et al., 2007) e, assim, a ingestão de forragem foi mantida. $O$ peso de bocados apresentou correlação positiva com a ingestão de forragem em porcentagem de peso vivo $(0,86 ; \mathrm{P}<0,05)$. Assim, é esperado que ocorra maior ingestão de forragem quando os animais em pastejo conseguem realizar bocados mais pesados, pois o tamanho do bocado (massa) é considerado a menor e mais simples unidade que compõe o consumo. De forma geral, o bocado é afetado pelas características estruturais do pasto, que determinam a profundidade de exploração pelos animais em pastejo (Da SILVA, 2009). Uma vez que a oferta de forragem e o seu valor nutritivo não sejam limitantes, a ingestão de matéria seca dependerá das relações entre tamanho do bocado (profundidade) e a taxa com que esses bocados são realizados.

\section{CONCLUSÃO}

Novilhas em pasto de milheto manejado com 600 ou $1.000 \mathrm{~kg} \mathrm{ha}^{-1}$ de MS de lâminas foliares apresentam capacidade de ingestão de forragem semelhante e qualquer um desses valores pode ser usado na condução do manejo da pastagem. A capacidade de ingestão de forragem é reduzida quando o milheto, em ambas as massas de lâminas foliares, passa do estádio vegetativo para o reprodutivo.

\section{REFERÊNCIAS}

ALLDEN, W.G.; WHITTAKER, A.M. The determinants of herbage intake by grazing sheep: the interrelationship of factors 
influencing herbage intake and availability. Australian Journal of Agricultural Research, v.21, p.755, 1970.

ASSOCIATION OF OFFICIAL ANALYTICAL CHEMISTSAOAC. Official methods of analysis. 14 ed. Washington, 1984. 1141p. 1995.

CARLOTO, M.N. et al. Perfilhamento e acúmulo de forragem de capim-xaraés submetido a intensidades de pastejo. In: REUNIÃO ANUAL DA SOCIEDADE BRASILEIRA DE ZOOTECNIA, 46., 2009, Maringá, PR. Anais... Maringá: Sociedade Brasileira de Zootecnia, 2009. CD-ROM.

CARVALHO, P.C.F. et al. Avanços metodológicos na determinação do consumo de ruminantes em pastejo. Revista Brasileira de Zootecnia, v.36, supl esp, p.151-170, 2007. Disponível em: $<$ http://www.scielo.br/scielo.php?script=sci_arttext\&pid=S1516$35982007001000016 \& \operatorname{lng}=$ pt\&nrm=iso $>$. Acesso em 13 jan. 2010. doi: 10.1590/S1516-35982007001000016.

CARVALHO, P.C.F. et al. Importância da estrutura da pastagem na ingestão e seleção de dietas pelo animal em pastejo. In: MATTOS, W.R.S. (Org.). A produção animal na visão dos brasileiros. Piracicaba: Sociedade Brasileira de Zootecnia, 2001. p.853-871.

CARVALHO, P.C.F; MORAES, A. Comportamento ingestivo de ruminantes: bases para o manejo sustentável do pasto. In: CECATO, U.; JOBIM, C.C. (Org.). Manejo sustentável em pastagem. Maringá: Universudade Estadual de Maringá, 2005. V.1, p.1-20.

Da SILVA, S.C. Conceitos básicos sobre sistemas de produção animal em pasto. In: Da SILVA, S.C. et al. (Eds.). SIMPÓSIO SOBRE O MANEJO DE PASTAGENS, 25., 2009, Piracicaba, SP. Anais... Piracicaba: Fundação de Estudos Agrários Luiz de Queiroz, 2009. p.7-36.

Da SILVA, S.C. Understanding the dynamics of herbage accumulation in tropical grass species: the basis for planning efficient grazing management practices. In: INTERNATIONAL SYMPOSIUM ON GRASSLAND ECOPHYSIOLOGY AND GRAZING ECOLOGY, 2., 2004, Curitiba, PR. Proceedings... Curitiba: Universidade Federal do Paraná, 2004. CD-ROM.

EMBRAPA. Centro Nacional de Pesquisa de Solos. Sistema brasileiro de classificação de solos. Brasília: EMBRAPA, 1999. 412p.

EUCLIDES, V.P.B. et al. Avaliação de diferentes métodos de amostragem sob pastejo. Revista Brasileira de Zootecnia, v. 21, n.4, p.691-702, 1992.

FLORES, R.S. et al. Desempenho animal, produção de forragem e características estruturais dos capins marandu e xaraés submetidos a intensidades de pastejo. Revista Brasileira de Zootecnia, v.37, p. 1355-1365, 2008. Disponível em: <http:/ $/ \mathrm{www}$.scielo.br/scielo.php?script=sci_arttext\&pid=S1516$35982008000800004 \& \operatorname{lng}=\mathrm{pt} \& n r m=i$ so $>$. Acesso em 9 jan. 2010. doi: $10.1590 / \mathrm{S} 1516-35982008000800004$

HODGSON, J. Grazing management: science into practice. England: Longman Scientific \& Technical, 1990. 203 p.

HODGSON, J. Ingestive behaviour. In: Herbage intake handbook. Hurley:British Grassland Society, 1982. p.113138.
KOLLET, J.L. et al. Rendimento forrageiro e composição bromatológica de variedades de milheto (Pennisetum glaucum (L.) R. BR.). Revista Brasileira de Zootecnia, v.35, n.4, p.1308-1315, 2006. Disponível em: <http://www.scielo.br/ scielo.php? script=sci_art text \& pid=S 1516 $35982006000500008 \& 1 n g=p t \& n r m=i s o>$. Acesso em $21 \mathrm{fev}$. 2010. doi: $10.1590 / \mathrm{S} 1516-35982006000500008$.

MENDES, A.R. et al. Comparação de três diferentes indicadores na estimativa da digestibilidade parcial e total de novilhos. In: REUNIÃO ANUAL DA SOCIEDADE BRASILEIRA DE ZOOTECNIA, 38., 2001, Piracicaba, SP. Anais... São Paulo: Sociedade Brasileira de Zootecnia, 2001. CD-ROM. Nutrição de Ruminantes.

MOTT, G.O.; LUCAS, H.L. The design, conduct, and interpretation of grazing trials in cultivated and improved pastures. In: INTERNATIONAL GRASSLAND CONGRESS, 6., 1952, Pennsylvania. Proceedings... Pennsylvania: State College, 1952. p.1380-1385.

NRC - NATIONAL RESEARCH COUNCIL. Nutrient requirement of beef cattle. 7.ed. Washington: National Academy, 1996. 242p.

PENNING, P.D. Animal-based techniques for estimating herbage intake. In: PENNING, P.D. (Ed.). Herbage intake handbook. 2.ed. Reading: The British Grassland Society, 2004. p.53-94.

POPPI, D.P.; McLENNAN, S.R. Protein and energy utilization by ruminants at pasture. Journal of Animal Science, v.73, n.1, p.278-290, 1995.

RIZO, L.M. et al. Desempenho de pastagem nativa e pastagem sobres-semeada com forrageiras hibernais com ou sem glifosato. Ciência Rural, v.34, n.6, p.1921-1926, 2004. Disponível em: $<$ http://www.scielo.br/scielo.php?script=sci_arttext\&pid=S0103$84782004000600039 \& \operatorname{lng}=$ pt\&nrm=iso $>$. Acesso em $11 \mathrm{fev}$. 2010. doi: $10.1590 / \mathrm{S} 0103-84782004000600039$.

SANTOS, D.T. et al. Suplementos energéticos para recria de novilhas de corte em pastagens anuais. Desempenho animal. Revista Brasileira de Zootecnia, v.34, n.1, p.209-219, 2005. Disponível em: <http://www.scielo.br/scielo.php?script=sci_arttext\&pid=S1516$35982004000900023 \& \operatorname{lng}=$ pt\&nrm=iso $>$. Acesso em 15 fev. 2010. doi: $10.1590 / \mathrm{S} 1516-35982004000900023$.

SAS Institute. Statistical analysis system user's guide. Version 6.08. Cary: Statistical Analysis System Institute, 1996. $1014 \mathrm{p}$.

STOBBS, T.H. The effects of plant structure on the intake of tropical pastures. I. Variation in the bite size of grazing cattle. Australian Journal of Agricultural Research, v.24, p.809819, 1973.

TILLEY, J.M.A.; TERRY, R.A. A two-stage technique for the "in vitro" digestion of forage crop. Journal British Grassland Society, v.18, n.2, p.104-111, 1963.

VAN SOEST, P.J. Plant, animal and environment. In: Nutritional ecology of the ruminant. 2.ed. Ithaca: Cornell University, 1994. p.77-92.

WILLIANS, C.H. et al. The determination of chromic oxide in faeces samples by atomic absorption spectrophotometry. Journal Animal Science, v.59, n.3, p.381-385, 1962. 